\title{
Pengaruh Pembelajaran Cooperative Problem Solving Berbantuan Media Virtual Phet terhadap Motivasi Berprestasi dan Kemampuan Pemecahan Masalah Fisika Siswa Kelas X MIPA SMAN 1 Bengkulu Selatan
}

\author{
Reza September Hotman, Irwan Koto, Nyoman Rohadi \\ Program Studi Pendidikan Fisika FKIP Universitas Bengkulu \\ E-mail: reza09hotman@gmail.com
}

\begin{abstract}
ABSTRAK
Penelitian ini bertujuan untuk 1) mengetahui perbedaan motivasi berprestasi antara siswa yang dibelajarkan dengan model Cooperative Problem Solving berbantuan media virtual PhET dan model Cooperative Problem Solving berbantuan media konvensional dan 2) untuk mengetahui perbedaan kemampuan pemecahan masalah antara siswa yang dibelajarkan dengan model Cooperative Problem Solving berbantuan media virtual PhET dan model Cooperative Problem Solving berbantuan media konvensional. Penelitian ini merupakan penelitian kuasi eksperimen dengan dua desain yaitu desain posttest only control group design untuk variabel motivasi berprestasi dan desain nonequivalent control group design untuk variabel kemampuan pemecahan masalah. Populasi penelitian ini adalah 153 siswa kelas X MIPA SMAN 1 Bengkulu Selatan. Pengambilan sampel penelitian ini menggunakan teknik purposive sampling untuk memperoleh dua kelas: kelas X MIPA 2 yang berjumlah 30 siswa sebagai kelas eksperimen dan kelas X MIPA 5 yang berjumlah 31 siswa sebagai kelas kontrol. Data diperoleh dari tes kemampuan pemecahan masalah yang berbentuk essay dan angket motivasi berprestasi. Hasil penelitian menunjukkan bahwa: (1) Tidak terdapat perbedaan kemampuan pemecahan masalah yang signifikan antara siswa yang dibelajarkan dengan pemelajaran CPS berbantuan media virtual PhET dan siswa yang dibelajarkan dengan model CPS berbantuan media konvensional (2) Tidak terdapat perbedaan motivasi berprestasi yang signifikan antara siswa yang dibelajarkan dengan pemelajaran CPS berbantuan media virtual PhET dan siswa yang dibelajarkan dengan model CPS berbantuan media konvensional
\end{abstract}

Kata kunci: Pembelajaran Cooperative Problem Solving, Media Virtual PhET, Motivasi Berprestasi, Kemampuan Pemecahan Masalah.

\begin{abstract}
This study aims: 1) to determine the difference of achievement motivation between students who are taught by Cooperative Problem Solving model with PhET virtual media and Cooperative Problem Solving model with conventional media and 2) to investigate the difference of problem solving ability between students who are taught by Cooperative Problem Solving model with PhET virtual media and model of Cooperative Problem Solving with conventional media. This research is a quasi experimental research with two designs namely posttest only control group design for achievement motivation variable and nonequivalent control group design for problem solving abilitiy variable. The population of this study is 153 students of class $\mathrm{X}$ MIPA at SMAN 1 South Bengkulu. Sampling of this research use purposive sampling technique to obtain two classes: X MIPA 2 which amounted to 30 students as experiment class and class X MIPA 5 which amounted to 31 student as control class. The result data was obtained from problem-solving ability test in the form of essay and questionnaire of achievement motivation. The result showed that: (1) There is no significant difference in problem solving ability among students who were taught by CPS learning with virtual PHET media and students who were taught by CPS learning with conventional media (2) There is no significant difference in achievement motivation between students who were taught by CPS learning with virtual PHET media and students who were taught by CPS learning with conventional.
\end{abstract}

Keywords: Cooperative Problem Solving Learning, PhET Virtual Media, Achievement Motivation, Problem Solving Ability.

\section{PENDAHULUAN}

Pendidikan merupakan suatu proses perubahan sikap dan perilaku seseorang dalam upaya mendewasakan manusia melalui proses pembelajaran. Undang-Undang Nomor 20 Tahun 2003 tentang Sistem Pendidikan Nasional menyebutkan bahwa pendidikan nasional berfungsi mengembangkan 
kemampuan dan membentuk watak serta peradaban bangsa dan bertujuan untuk berkembangnya potensi siswa agar menjadi manusia yang beriman dan bertakwa kepada Tuhan yang Maha Esa, berakhlak mulia, sehat, berilmu, cakap, kreatif, mandiri, dan menjadi warga negara yang demokratis serta bertanggung jawab. Maka untuk mewujudkan tujuan pendidikan nasional ini banyak hal yang harus diinovasi dalam dunia pendidikan mulai dari peningkatan sumber daya manusia baik guru maupun penyelenggara pendidikan, fasilitas sekolah dan yang terutama diperlukan pengembangan kurikulum termasuk kurikulum 2013.

Pada kurikulum 2013 terdapat Standar Isi yang ditetapkan dalam Peraturan Menteri Pendidikan dan Kebudayaan Republik Indonesia (Permendikbud) Nomor 21 Tahun 2016, Standar Proses dalam Permendikbud Nomor 22 Tahun 2016, dan Standar Penilaian dalam Permendikbud Nomor 23 Tahun 2016. Dalam peraturan ini proses pembelajaran diharapkan mampu menghasilkan lulusan yang memenuhi Standar Kompetensi Lulusan yang berkompetensi di ranah sikap, pengetahuan, dan keterampilan.

Berdasarkan observasi di kelas dan wawancara dengan guru fisika di SMAN 1 Bengkulu Selatan, kurikulum 2013 sudah diterapkan di sekolah. Model pembelajaran yang digunakan bervariasi (Problem Based Learning, Discovery learning, dan Inkuiri) sesuai materi yang dibelajarkan. Namun, pelaksanaannya dalam pembelajaran belum maksimal. Siswa belum terlibat aktif dalam masalah yang diberikan dan penggunaan media pembelajaran masih jarang dan belum maksimal.

Kegiatan praktikum fisika dilakukan di laboratorium IPA. Karena terdapat alat-alat praktikum yang rusak, misalnya peralatan untuk percobaan gerak harmonik yaitu pegas dan beberapa alat jumlahnya kurang maka akan menghambat kegiatan praktikum. Selain itu, pada materi pembelajaran fisika yang bersifat abstrak seperti pada konsep listrik statis tentang muatan listrik, praktikum tidak dapat dilakukan sehingga guru hanya menjelaskan materi saja tanpa adanya praktikum.

Belum maksimalnya proses pembelajaran ini mengakibatkan kemampuan siswa dalam memecahkan masalah melalui kegiatan eksperimen masih rendah. Misalnya dalam mengusai konsep-konsep fisika yang terkait dengan masalah yang diberikan. Selain itu hal ini berdampak pada kurangnya minat siswa yang berdapak pada kurangnya motivasi siswa untuk berprestasi. Siswa tidak memiliki keinginan yang kuat untuk menyelesaikan tugas-tugas yang diberikan oleh guru sehingga taraf prestasi siswa di mata pelajaran fisika tergolong rendah.

Salah satu upaya yang dapat dilakukan untuk meningkatkan kemampuan pemecahan masalah siswa adalah dengan menciptakan proses pembelajaran yang dapat memberikan keleluasaan pada siswa agar lebih aktif dalam pemecahan masalah selama proses pembelajaran. Salah satu model pembelajaran yang efektif agar siswa lebih aktif dalam memecahkan masalahadalah model pembelajaran Cooperative Problem Solving (CPS). Pada model CPS terdapat kontak fisik antar siswa, siswa mendiskusikan masalah satu sama lain, membantu satu sama lain untuk memecahkan masalah dan berbagi tugas secara kompak [1]. Penerapan model CPS ini mampu meningkatkan kemampuan pemecahan masalahmelalui pembelajaran fisika yaitu kemampuan siswa menggunakan pengetahuan-pengetahuan dan konsep-konsep cahaya yang dipelajarinya untuk menemukan solusi atas masalah-masalah "kaya konteks" (context -rich problems) yang menghitung sejumlah kuantitas mengenai objek atau peristiwa nyata [2].

Penggunaan model pembelajaran saja masih belum optimal untuk meningkatkan kemampuan pemecahan masalah dan minatbelajar siswa. Sehingga diperlukan bantuan media pembelajaran terutama yang berbasis komputer untuk menarik minat dan meningkatkan motivasi berprestasi siswa. Media pembelajaran yang cocok untuk pembelajaran fisika adalah media laboratorium virtual [3]. Pembelajaran yang menggunakan metode simulasi media virtual merupakan media yang efektif dalam mengaplikasikan kurikulum 2013 mengingat melihat siswa yang memiliki kecenderungan pada komputer. Media virtual yang dapat digunakan pada pembelajaran fisika adalah PhET yang merupakan simulasi interaktif fenomena-fenomena fisis yang disusun oleh para ahli berdasarkan berbasis riset yang telah dilakukan [4].

Hasil penelitian Muhammad,dkk menyatakan siswa yang menggunakan metode penerapan media simulasi PhET memiliki hasil belajar yang lebih tinggi dibandingkan siswa yang tidak menggunakan media simulasi PhET [5]. Pemanfaatan media komputer dapat meningkatkan motivasi berprestasi IPA Fisika siswa[6]. Oleh karena itu, pada penelitian ini model Cooperative Problem Solving (CPS) akan dikolaburasikan dengan media virtual PhET. Penggunaan model Cooperative Problem Solving berbantuan Media virtual PhET diharapkan berpengaruh terhadap motivasi berprestasi dan kemampuan pemecahan masalah siswa dalam pembelajaran fisika.

Rumusan masalah penelitian ini yaitu: 1) apakah terdapat perbedaan motivasi berprestasi antara siswa yang dibelajarkan dengan model Cooperative Problem Solving berbantuan media virtual PhET dan siswa yang dibelajarkan dengan model Cooperative Problem Solving berbantuan media konvensional di kelas X MIPA di SMAN 1 Bengkulu Selatan? 2) apakah terdapat perbedaan kemampuan pemecahan masalah antara 
siswa yang dibelajarkan dengan model Cooperative Problem Solving berbantuan media virtual PhET dan siswa yang dibelajarkan dengan model Cooperative Problem Solving berbantuan media konvensional di kelas X MIPA di SMAN 1 Bengkulu Selatan?

\section{METODE PENELITIAN}

Jenis penelitian ini adalah eksperimen dengan dua desain quasi experimental design, yaitu posttest only control group design untuk variabel motivasi berprestasi (tabel 2.1) dan nonequivalent control group design untuk variabel kemampuan pemecahan masalah (tabel 2.2).

Tabel 1. Postest Only Control Group Design

\begin{tabular}{cccc}
\hline Kelas & Perlakuan & Posttest \\
\hline Kelas Eksperimen & $\mathrm{X}_{1}$ & $\mathrm{O}_{1}$ \\
\hline Kelas Kontrol & $\mathrm{X}_{2}$ & $\mathrm{O}_{2}$ \\
\hline & Tabel 2. 2. Nonequivalent & Control Group Design \\
\hline Kelas & Pretest & Perlakuan & Posttest \\
\hline Kelas Eksperimen & $\mathrm{O}_{1}$ & $\mathrm{X}_{1}$ & $\mathrm{O}_{2}$ \\
\hline Kelas Kontrol & $\mathrm{O}_{3}$ & $\mathrm{X}_{2}$ & $\mathrm{O}_{4}$ \\
\hline
\end{tabular}

Pada penelitian ini yang menjadi populasi penelitian adalah siswa kelas X MIPA SMA Negeri 1 Bengkulu Selatan tahun ajaran 2017/2018 yang berjumlah 5 kelas. Sampel diambil menggunakan teknik purposive sampling, sehingga diperoleh 2 kelas dari 5 kelas X MIPA. Kelas eksperimen akan mendapatkan pembelajaran dengan model CPS berbantuan media virtual PhET. Sedangkan kelas kontrol akan mendapatkan pembelajaran dengan model CPS berbantuan media konvensional.

Sebelum diberikan ke siswa, instrumen tes KPM dan angket motivasi berprestasi divalidasi isi terlebih dahulu oleh tiga ahli yaitu satu dosen pendidikan fisika dan duaguru mata pelajaran fisika. Selanjutnya, instrumen tes divalidasi empiris dengan diuji coba ke 23 siswa kelas XI MIPA 4 untuk mengetahui validitas, reliabilitas, tingkat kesukaran, dan daya pembeda butir soal.

Data penelitian ini berupa hasil tes KPM yang diperoleh dari pretest dan posttest KPM dan motivasi berprestasi yang diperoleh dari posttest angket motivasi berprestasi. Selanjutnya hasil pretest dan posttest tersebut diolah untuk dilakukan uji perbedaan (uji t) dengan terlebih dahulu memastikan bahwa data tersebut berdistribusi normal dan homogen. Data dianalisis dengan menggunakan Microsoft Excel untuk analisis tingkat kesukaran, daya pembeda butir soal dan pembuatan grafik serta dengan aplikasi SPSS versi 20 untuk uji validitas, reliabilitas, analisis deskriptif, uji normalitas, homogenitas dan uji hipotesis.

\section{HASIL DAN PEMBAHASAN}

3.1 Kemampuan Pemecahan Masalah

Tabel 3.1 menunjukkan analisis deskriptif hasil tes KPM kelas eksperimen dan kelas kontrol.

Tabel 2. Data Deskriptif KPM

\begin{tabular}{cccccc}
\hline \multirow{2}{*}{ Kelas } & Data & Nilai Min & Nilai Max & Rata-Rata & $\begin{array}{c}\text { Standar } \\
\text { Deviasi }\end{array}$ \\
\hline \multirow{2}{*}{ Eksperimen } & Pretest & 10 & 48 & 22,47 & 9,691 \\
\cline { 2 - 6 } & Posttest & 26 & 85 & 59,67 & 13,852 \\
\hline \multirow{2}{*}{ Kontrol } & Pretest & 10 & 42 & 22,77 & 6,469 \\
\cline { 2 - 6 } & Posttest & 25 & 94 & 61,03 & 14,838 \\
\hline
\end{tabular}

Berdasarkan uji normalitas menggunakan aplikasi SPSS dengan uji kolmogrov-Smirnov dengan koreksi Liliefors didapatkan bahwa pretest dan posttest kelas eksperimen berdistribusi normal ditunjukkan dengan Signifikansi (sig.2-tailed) > 0,05. Hasil uji normalitas data kemampuan pemecahan masalah dapat dilihat pada Tabel 3.2.

Tabel 3. Hasil Uji Normalitas Data Kemampuan Pemecahan Masalah

\begin{tabular}{cccc}
\hline Kelas & Data & Signifikansi & Distribusi data \\
\hline \multirow{2}{*}{ Eksperimen } & Pretest & 0,110 & Normal \\
\cline { 2 - 4 } & Posttest & 0,200 & Normal \\
\hline \multirow{2}{*}{ Kontrol } & Pretest & 0,200 & Normal \\
\cline { 2 - 4 } & Posttest & 0,200 & Normal \\
\hline
\end{tabular}


Kemudian uji homogenitas menggunakan aplikasi SPSS versi 20 melalui analisis anova one way. Berdasarkan hasil analisis tersebut diperoleh bahwa varians kedua data adalah homogen ditunjukkan dengan nilai signifikansi (sig.2-tailed) > 0,05. Hasil uji homogenitas KPM dapat dilihat pada Tabel 3.3.

Tabel 4. Hasil Uji Homogenitas KPM

\begin{tabular}{ccc}
\hline Data & Signifikansi & Keterangan \\
\hline Pretest KPM & 0,053 & Homogen \\
\hline Postest KPM & 0,798 & Homogen \\
\hline
\end{tabular}

Dikarenakan skor pretest dan posttest KPM berdistribusi normal dan homogen, maka uji t bisa dilakukan. Uji t dianalisis menggunakan aplikasi SPSS versi 20. dengan Independent Samples t-Test. Berdasarkan hasil uji beda tersebut diperoleh bahwa tidak terdapat perbedaan kemampuan pemecahan masalah yang signifikan antara kelas eksperimen dan kelas kontrol. Hal ini ditunjukkan dengan nilai signifikansi (Sig.2-tailed) sebesar 0,712 > 0,05. Grafik rata-rata pretest dan posttest pada kelas eksperimen dan kelas kontrol ditunjukkan pada Gambar 3.1.

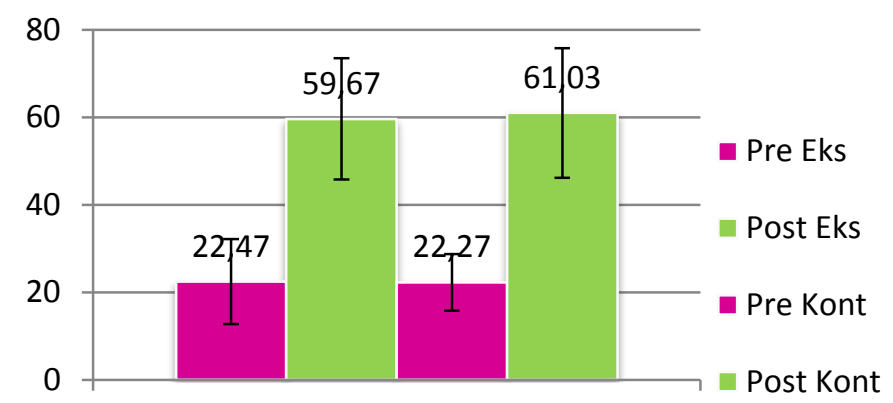

Gambar 1. Grafik skor rata-rata pretest dan posttest KPM

Tidak terdapatnya pengaruh yang penggunaan media virtual PhET yang signifikan terhadap kemampuan pemecahan masalah siswa ini bertolak belakang dengan hasil penelitian Darti, Fuadunazmi, dan P (2015) yang menyimpulkan bahwa penggunaan media laboratorium virtual fisika berpengaruh terhadap kemampuan pmecahan masalah siswa [7].

Terdapat beberapa faktor yang menyebabkan tidak terdapat perbedaan kemampuan pemecahan masalah yang signifikan antara kelas eksperimen dan kelas kontrol. Pertama, karena kedua kelas sama-sama diberi perlakuan dengan pembelajaran model CPS, dimana model pembelajaran ini memang bertujuan untuk melatihkan kemampuan pemecahan masalah siswa. Sehingga baik kelas eksperimen maupun kelas kontrol sama-sama mengalami peningkatan dalam kemampuan pemecahan masalah fisika.

Selanjutnya, penggunaan media virtual PhET sebenarnya lebih ke arah untuk mempermudah siswa dalam memahami konsep yang dipelajarinya. Penggunaan media laboratorium virtual berpengaruh terhadap penguasaan konsep dan kemampuan berpikir kreatif siswa pada materi getaran dan gelmbang kelas VII SMPN 1 Alas Barat tahun ajaran 2013/2014 [8]. Selain itu, pembelajaran menggunakan media virtual lebih efektif untuk melatihkan keterampilan proses sains siswa. Faktor selanjutnya yang menyebabkan tidak terdapat pengaruh media virtual terhadap kemampuan pemecahan masalah kelas eksperimen dan kelas kontrol yaitu, karena siswa belum terbiasa menggunakan aplikasi PhET Sehingga siswa perlu dilatih terlebih dahulu. Hal ini membuat waktu yang dibutuhkan dalam pembelajaran kelas eksperimen lebih lama dibandingkan dengan kelas kontrol. Berbeda dengan situasi pembelajaran pada kelas kontrol, siswa tidak menggunakan media PhET dalam pembelajaran CPS sehingga siswa tidak perlu menyesuaikan diri dengan aplikasi PhET dan hanya perlu fokus dalam langkah-langkah pemecahan masalah CPS saja.

\section{a. Motivasi Berprestasi Siswa}

Tabel 3.4 menunjukkan hasil analisis deskriptif motivasi berprestasi kelas eksperimen dan kelas kontrol. Tabel 5. Data Deskriptif Motivasi Siswa

\begin{tabular}{ccccccc}
\hline Kelas & Data & Nilai Min & Nilai Max & Rata-Rata & $\begin{array}{c}\text { Standar } \\
\text { Deviasi }\end{array}$ & \% Perbedaaan \\
\cline { 1 - 5 } Eksperimen & Postest & 49 & 75 & 60,40 & 5,170 & \multirow{2}{*}{$0,83 \%$} \\
\hline Kontrol & Postest & 48 & 76 & 59,90 & 6,090 & \\
\hline
\end{tabular}

Berdasarkan uji normalitas menggunakan aplikasi SPSS dengan uji kolmogrov-Smirnov dengan koreksi Liliefors didapatkan bahwa posttest motivasi berprestasi kelas eksperimen berdistribusi normal ditunjukkan 
dengan Signifikansi (sig.2-tailed) > 0,05. Hasil uji normalitas data kemampuan pemecahan masalah dapat dilihat pada Tabel 3.5.

Tabel 6. Hasil Uji Normalitas Motivasi Berprestasi

\begin{tabular}{cccc}
\hline Kelas & Data & Signifikansi & Distribusi data \\
\hline Eksperimen & Postest & 0,200 & Normal \\
\hline Kontrol & Postest & 0,200 & Normal \\
\hline
\end{tabular}

Kemudian uji homogenitas menggunakan aplikasi SPSS versi 20. Dengan analisis anova one way. Berdasarkan hasil analisis tersebut diperoleh bahwa varians kedua data adalah homogen ditunjukkan dengan nilai signifikansi (sig.2-tailed) > 0,05. Hasil uji homogenitas motivasi berprestasi menunjukkan signifikansi (2-tailed) sebesar 0,223 sehingga data dinyatakan homogen.

Dikarenakan skor posttest motivasi berprestasi berdistribusi normal dan homogen, maka uji t bisa dilakukan. Uji beda dianalisis menggunakan aplikasi SPSS versi 20. dengan Independent Samples t-Test. Berdasarkan hasil uji beda tersebut diperoleh bahwa tidak terdapat perbedaan motivasi berprestasi yang signifikan antara kelas eksperimen dan kelas kontrol. Hal ini ditunjukkan dengan nilai signifikansi (Sig.2tailed) sebesar 0,733 >0,05. Grafik rata-rata posttest motivasi berprestasi pada kelas eksperimen dan kelas kontrol ditunjukkan pada Gambar 3.2.

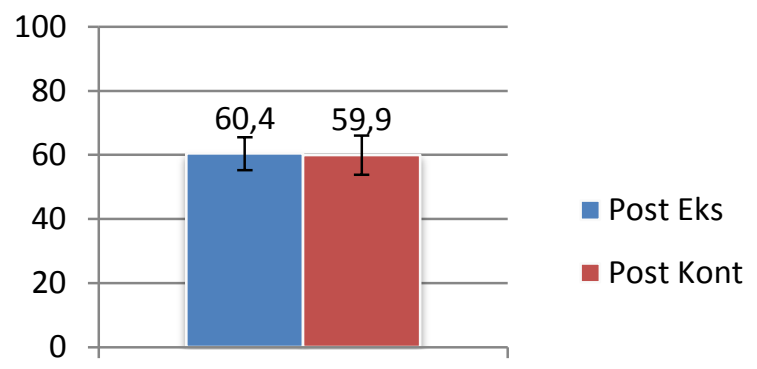

Gambar 2. Grafik rata-rata posttest motivasi berprestasi

Selain menggunakan uji t sampel independen, dilakukan perhitungan persentase perbedaan (\% difference) dari rata-rata posttest motivasi berprestasi kelas eksperimen dan kelas kontrol. Persentase perbedaan motivasi berprestasi kedua sampel sangat kecil yaitu $0,83 \%$. Dengan demikian berdasarkan uji $\mathrm{t}$ sampel independen dan perhitungan $\%$ perbedaan, tidak terdapat perbedaan yang signifikan antara motivasi berprestasi kelas eksperimen dan kelas kontrol.

Hal ini karena terdapat beberapa faktor yang menyebabkan tidak adanya perbedaan yang signifikan antara rata-rata motivasi berprestasi kelas eksperimen dan kelas kontrol. Pertama, karena belum terbiasanya siswa menggunakan media virtual PhET, sehingga ada beberapa siswa yang kurang termotivasi untuk mengikuti pembelajaran pada kelas eksprimen.

Faktor lain yang menyebabkan tidak terdapat perbedaan motivasi berprestasi kelas eksperimen dan kelas kontrol adalah karena model pembelajaran yang diberikan pada kedua kelas adalah sama, yaitu Cooperative Problem Solving sehingga jenis tugas atau soal diskusi yang diberikan untuk kedua kelas sama, yaitu sesuai dengan langkah-langkah pembelajaran CPS dan indikator kemampuan pemecahan masalah. Sehingga tingkat kesulitan soal diskusi yang mempengaruhi motivasi berprestasi kedua kedua kelas adalah sama.

Selain itu, penggunaan media virtual PhET sejatinya bertujuan untuk mengatasi ketidaksediaan laboratorium riil untuk materi pembelajaran yang bersifat abstrak. Laboratorium virtual dapat menjadi media untuk membantu pengajar maupun instruktur dalam melaksanakan praktikum di sekolah. Selain itu menggunakan laboratorium virtual memiliki kelebihan di mana lebih menghemat dana dan tidak harus mengganti alat praktikum jika terdapat kerusakan [9].

\section{KESIMPULAN DAN SARAN \\ 4.1 Kesimpulan}

Berdasarkan permasalahan dan hasil analisis data, dapat disimpulkan bahwa: (1) Tidak terdapat perbedaan kemampuan pemecahan masalah yang signifikan antara siswa yang dibelajarkan dengan pemelajaran CPS berbantuan media virtual PhET dan siswa yang dibelajarkan dengan model CPS berbantuan media konvensional (2) Tidak terdapat perbedaan motivasi berprestasi yang signifikan antara 
siswa yang dibelajarkan dengan pemelajaran CPS berbantuan media virtual PhET dan siswa yang dibelajarkan dengan model CPS berbantuan media konvensional.

\subsection{Saran}

Adapun saran yang dapat peneliti berikan dari penelitian ini sebagai berikut: 1) guru hendaknya dapat memilih model pembelajaran yang dapat meningkatkan kemampuan pemecahan masalah siswa. Salah satu alternatif model pembelajaran tersebut adalah model Cooperative Problem Solving, 2) perlu dilakukan penelitian lebih lanjut tentang penggunaan model Cooperative Problem Solving berbantuan media virtual PhET pada pembelajaran fisika pada konsep yang lain, dan 3) guru perlu mengenalkan kepada siswa media virtual PhET dalam pembelajaran fisika.

\section{UCAPAN TERIMA KASIH}

Terima kasih penulis sampaikan kepada bapak Irwan Koto selaku pembimbing utama dan bapak Nyoman Rohadi selaku pembimbing pendamping yang telah membimbing dan memberikan saran sera masukkan selama proses penelitian ini.

\section{DAFTAR PUSTAKA}

[1] Heller, K., \& Heller, P. (2010). Cooperative Problem Solving In Physics: A User's Manual. Tersedia: Https://Www.Aapt.Org/Conferences/Newfaculty/Upload/Coop-Problem-SolvingGuide.Pdf.

[2] Kulsum, U., \& Nugroho, S. E. (2014). Penerapan Model Pembelajaran Cooperative Problem Solving Untuk Meningkatkan Kemampuan Pemahaman Konsep Dan Komunikasi Ilmiah Siswa Pada Mata Pelajaran Fisika. Unnes Physics Education Journal, Vol. 3 No. 2. Hal.7475.

[3]Sugiana, I. N., Harjono, A., Sahidu, H., \& Guunawan. (2016). Pengaruh Model Pembelajaran Generatif Berbantuan Media Laboratorium Virtual Terhadap Penguasaan Konsep Fisika Siswa Pada Materi Momentum Dan Impuls. Jurnal Pendidikan Fisika Dan Teknologi, Vol. 2 No. 2 Hal. 61-65.

[4]Wisudawati, A. W., \& Sulistyowati, E. (2014). Metodologi Pembelajaran IPA . Jakarta: PT Bumi Aksara.

[5]Maulida, E. A., \& Suliyanah. (2016). Profil Miskonsepsi Siswa Dalam Model ECIRR Berbantuan Phet Simulation Pada Materi Momentum, Impuls Dan Tumbukkan. Jurnal Inovasi Pendidikan Fisika .

[6]Erlanggono, E., Kurniawan, S. E., \& Sriyono. (2012). Peningkatan Motivasi Berprestasi IPA Fisika Dengan Memanfaatkan Computer Assisted Instruction (CAI) Padasiswa SMP Negeri 6 Purworejo Tahun Pelajaran 2012/2013. Radiasi, Vol. 2 No. 1 Hal. 31-34.

[7]Darti, E. Y., Fuadunazmi, M., \& P, D. S. (2015). PENGARUH PENGGUNAAN MEDIALABORATORIUMVIRTUAL FISIKA TERHADAP KEMAMPUAN PEMECAHAN MASALAH SISWA. Jurnal Ilmiah Pendidikan Fisika "Lensa", 2338-4417.

[8]Hermansayh, Gunawan, \& Herayati, L. (2015). Pengaruh Penggunaan Laboratorium Virtual Terhadap Penguasaan Konsep Dan Kemampuan Berpikir Kreatif Siswa Pada Materi Getaran Dan Gelombang . Jurnal Pendidikan Fisika Dan Teknologi, Vol. 1 No. 2 Hal. 97-102.

[9]Mirdayanti, R., \& Murni. (2017). Kajian Penggunaan Laboratorium Virtual Berbasis Simulasi Sebagai Upaya Mengatasi Ketidak-Sediaan Laboratorium . Jurnal Visipena Vol. 8 No. 2 , 323-330. 